Check for updates

Cite this: RSC Adv., 2018, 8, 31261

Received 28th May 2018

Accepted 26th August 2018

DOI: $10.1039 / \mathrm{c} 8 \mathrm{ra0} 4526 \mathrm{~g}$

rsc.li/rsc-advances

\section{Detection of $\mathrm{SO}_{2}$ derivatives using a new chalco- coumarin derivative in cationic micellar media: application to real samples $\uparrow$}

\author{
Marisol Gómez, (ID *ab Margarita E. Aliaga, (D) a Verónica Arancibia, ${ }^{a}$ Alexis Moya, ${ }^{a}$ \\ Camilo Segura, ${ }^{c}$ Marco T. Nuñez, ${ }^{d}$ Pabla Aguirre, ${ }^{d}$ Edgar Nagles (iD) \\ and Olimpo García-Beltrán (D) *e
}

\begin{abstract}
A new probe (E)-7-(diethylamino)-3-(3-(thiophen-2-yl)acryloyl)-2H-chromen-2-one (ChC16) was synthesized and studied as a turn-on fluorescent probe, based on a Michael addition mechanism for sensing $\mathrm{SO}_{2}$ derivatives, which is favored in the presence of cationic micellar media such as cetylpyridinium bromide (CPB). The probe showed high selectivity and sensitivity toward bisulfite over other anions and biothiols, including cysteine (Cys), homocysteine (Hcy) and glutathione (GSH), with a detection limit of $240 \mathrm{nM}$. Moreover, the probe showed great potential for its practical application in the detection of bisulfite in real samples, such as dry white wine, and in bioimaging.
\end{abstract}

\section{Introduction}

Sulfur dioxide $\left(\mathrm{SO}_{2}\right)$ derivatives, such as sulfite $\left(\mathrm{SO}_{3}{ }^{-2}\right)$ and bisulfite $\left(\mathrm{HSO}_{3}{ }^{-}\right)$ions, have been largely used as preservatives for many foodstuffs, drinks and medications. ${ }^{1}$ However, it is well-known that all the $\mathrm{SO}_{2}$ forms can potentially cause health problems. Specifically, it has been reported that elevated quantities of sulfite can cause asthma and allergic reactions in some people, including difficulty in breathing, urticaria and gastrointestinal discomfort. ${ }^{2-4}$

In this context, the Joint FAO/WHO Expert Committee on Food Additives has determined that an acceptable daily intake of sulfites should be lower than $0.7 \mathrm{mg} \mathrm{kg}^{-1}$ of body weight. ${ }^{5}$ Besides, since 1986 the FDA in the United States has demanded that any food or drink that contains a sulfite concentration bigger than $10 \mathrm{mg} \mathrm{L}^{-1}(125 \mu \mathrm{M})^{6}$ should be labelled. Therefore, the development of analytical methods that allow the detection and quantification of by-products of $\mathrm{SO}_{2}$ have gained great interest.

${ }^{a}$ Facultad de Química, Pontificia Universidad Católica de Chile, Vicuña Mackenna 4860, Santiago, 7820436, Chile

${ }^{b}$ Escuela de Obstetricia y Puericultura and Centro Integrativo de Biología y Química Aplicada (CIBQA), Universidad Bernardo OHiggins, General Gana 1702, Santiago, 8370993, Chile

${ }^{c}$ Department of Chemistry, Faculty of Sciences, Universidad de Chile, Santiago 7800024, Chile

${ }^{d}$ Biology Department, Faculty of Sciences, Universidad de Chile, Santiago 7800024, Chile

${ }^{e}$ Facultad de Ciencias Naturales y Matemáticas, Universidad de Ibagué, Carrera 22 Calle 67, Ibagué 730001, Colombia. E-mail: jose.garcia@unibague.edu.co

$\dagger$ Electronic supplementary information (ESI) available. See DOI: $10.1039 / \mathrm{c} 8 \mathrm{ra04526g}$
At this time, there are several conventional methods for this purpose, such as iodometric titration, ${ }^{7}$ chromatography, ${ }^{\mathbf{8}, 9}$ electrochemical analysis $\mathbf{1 0}^{\mathbf{1 0}}$ and flow injection analysis (FIA). ${ }^{\mathbf{1 3 , 1 4}}$ Nevertheless, the principal disadvantage of these methods is that the majority of them require sample pretreatment and the use of multiple reagents. Furthermore, in some cases, the detection process is very low and depends on high-cost instruments.

By contrast, the current use of fluorescent probes as a detection technique has acquired great relevance due to their high sensitivity and accuracy. In this context, novelty fluorescent probes have been developed by the detection of $\mathrm{SO}_{2}$ derivatives, ${ }^{15-19}$ mainly based on reactions with $\mathrm{HSO}_{3}{ }^{-} / \mathrm{SO}_{3}{ }^{2-}$. Some examples reported in the literature are summarized in Table S1 (ESI $\dagger$ ), and among this information we are interested in those that undergo a nucleophilic addition to " $\mathrm{C}=\mathrm{C}$ " double bond, as a detection mechanism. Interestingly, Zhang et al. $(2013)^{20}$ reported promising studies in this area, using a cationic cetyltrimethylammonium bromide (CTAB) micelle, which created a hydrophobic microenvironment promoting the addition reaction from the sulfite to an activated olefin in aqueous solutions. Therefore, the selectivity and sensitivity of the probe improved considerably. More recently, we have reported new probes able to detect $\mathrm{SO}_{2}$-derivatives via a Michael-type addition reaction, which was also favored by micellar media. ${ }^{21}$ In particular, we demonstrated that typical interferences, such as glutathione (GSH) and cysteine (Cys) were inhibited by the presence of the cationic micelles of cetylpyridinium bromide (CPB) and zwitterionic micelle of sulfobetaine (SB3-14) and the detection limits improved considerably. Thus, we take advantage of this fact and we are presenting in this study a new coumarin-chalcone derivative (E)-7-(diethylamino)-3-(3-(thiophen-2-yl)acryloyl)-2H- 
chromen-2-one (ChC16). The latter would undergo a nucleophilic addition reaction of $\mathrm{SO}_{2}$-derivatives to its " $\mathrm{C}=\mathrm{C}$ " double bond, favored by the use of a cationic micelle.

\section{Results and discussion}

\subsection{Synthesis and characterization of probe (ChC16)}

We describe here a new probe ChC16 (Scheme 1), which was designed considering a diethylaminocoumarin unit, as the fluorophore, ${ }^{5}$ bound via a double bond $(\mathrm{C}=\mathrm{C})$ with a thiophene fragment. The bond $(\mathrm{C}=\mathrm{C})$ would be responsible for the recognition of $\mathrm{SO}_{2}$-derivatives via a nucleophilic addition reaction. The latter based on previous studies, which demonstrated that other chalco-coumarin derivatives were able to act as fluorescent sensors for biothiols based on Michael addition. ${ }^{22,23}$ Regarding the thiophene fragment, it is considered as a good moiety for Michael acceptor. In fact, studies demonstrated that 2-(2-nitrovinyl)thiophene is only a little less reactive than the well-known Michael acceptor trans $\beta$-nitrostyrene. ${ }^{24}$

The new compound ChC16 was synthesized in two steps, as shown in Scheme 1. Firstly, 4-diethylaminosalicylaldehyde (1) was condensed with ethyl acetoacetate (Knoevenagel) and cyclized obtaining the compound 3-acetyl-7-(diethylamino)-2Hchromen-2-one (2). ${ }^{25}$ Finally, ChC16 was synthetized by adaptations of a literature procedure ${ }^{26}$ and characterized by ${ }^{1} \mathrm{H}-\mathrm{NMR}$, ${ }^{13} \mathrm{C}-\mathrm{NMR}$ and HRMS (S1-S3; ESI $\dagger$ ).

\subsection{Absorption and emission properties of the probe (ChC16) in a micellar media of CPB}

The absorption and emission properties of the ChC16 derivative at neutral conditions, $20 \mathrm{mM}$ Britton-Robinson (BR) buffer ( $\mathrm{pH}$ $\approx 7$ ) containing $1 \%(\mathrm{v} / \mathrm{v})$ DMSO were assessed. Probe ChC16 exhibits an absorption band with a maximum at $450 \mathrm{~nm}$ (Fig. S4; ESI $\dagger$ ), a molar absorptivity $\left(\varepsilon_{450}\right)$ of $23888 \mathrm{~L} \mathrm{~mol}^{-1} \mathrm{~cm}^{-1}$ (Fig. S5; ESI $\dagger$ ) and a characteristic emission $\sim 500 \mathrm{~nm}$. In the presence of the micelle $\mathrm{CPB}$, the absorption band associated with ChC16 is well defined and centered at $460 \mathrm{~nm}$. Regarding the intensity of fluorescence emission (centered on $500 \mathrm{~nm}$ ), it considerably increased by CPB effect. As shown in Table 1, the quantum yields were determined to be 0.169 and 0.349 for ChC16 in absence and presence of CPB, respectively.

\subsection{Effect of $\mathrm{pH}$ on the fluorescence response of the probe ChC16 toward $\mathrm{SO}_{2}$-derivatives}

To ensure the optimal conditions to efficiently detect $\mathrm{SO}_{2}$ derivatives $\left(\mathrm{HSO}_{3}{ }^{-} / \mathrm{SO}_{3}{ }^{2-}\right)$ with the tested derivative (ChC16),

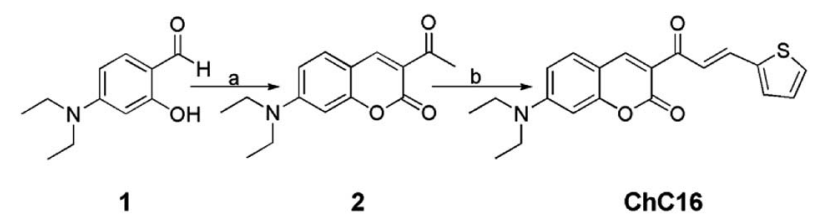

Scheme 1 Synthetic route for probe ChC16. Reagents and conditions: (a) ethyl acetoacetate, piperidine, $\mathrm{AcOH}, \mathrm{EtOH}$, reflux, 6 h; (b) 2-thiophenecarboxaldehyde, DCM, reflux, 12 h.
Table 1 Photophysical parameters of the tested fluorescent ChC16 in the absence and presence of $\mathrm{CPB}$ and $\mathrm{Na}_{2} \mathrm{SO}_{3}$ in aqueous solution

\begin{tabular}{llllll}
\hline$[\mathrm{CBP}](\mathrm{mM})$ & {$\left[\mathrm{Na}_{2} \mathrm{SO}_{3}\right](\mu \mathrm{M})$} & $\lambda_{\mathrm{Abs}}(\mathrm{nm})$ & $\lambda_{\mathrm{Emi}}(\mathrm{nm})$ & $\varepsilon\left(\mathrm{M}^{-1} \mathrm{~cm}^{-1}\right)$ & $\Phi$ \\
\hline- & - & 450 & 500 & 23888 & 0.169 \\
1.5 & - & 460 & 490 & 36034 & 0.349 \\
- & 500 & 450 & 500 & 28434 & 0.381 \\
1.5 & 500 & 460 & 490 & 31546 & 0.893
\end{tabular}

we evaluated the changes in the fluorescence intensity associated with it. The latter was carried out in the presence of $\mathrm{Na}_{2} \mathrm{SO}_{3}$, at different $\mathrm{pH}$ values. As it can be seen in Fig. 1, the fluorescence response of probe ChC16 alone was almost $\mathrm{pH}$ insensitive, whereas upon the interaction with $\mathrm{Na}_{2} \mathrm{SO}_{3}$ important changes were observed depending on the $\mathrm{pH}$ values, showing a high fluorescence response from $\mathrm{pH} 6$ to 9. In fact, a $\mathrm{pH}$ value of 7 was found to be appropriate for the bisulfite/ sulfite detection by probe ChC16. The latter suggests that this probe can successfully react with $\mathrm{HSO}_{3}{ }^{-} / \mathrm{SO}_{3}{ }^{2}$ and allow for them to be detected in physiological conditions.

Considering these results, we assessed the effect of adding increasing concentrations of $\mathrm{Na}_{2} \mathrm{SO}_{3}$ on the intensity of the emission band of ChC16 at $490 \mathrm{~nm}$, in the presence of CPB. As shown in Fig. 2(A), the emission band peak of probe in the presence of different concentrations of $\mathrm{Na}_{2} \mathrm{SO}_{3}$ (0-10 equivalent) gradually increased. The intensity of emission changed from 110 to 700 arbitrary units (see quantum yields in Table 1) and the reaction could be completed in $15 \mathrm{~min}$. As a result, a good linear relationship between them was observed; thus, based on this linearity (Fig. 2(B)), the detection limit was determined to be $240 \mathrm{nM}(\mathrm{S} / \mathrm{N}=$ 3). This value was lower to those reported in the literature for other probes for sulfite in the absence of the micellar medium. ${ }^{21,27}$

Regarding the stability of the method, this was mentioned in the Experimental section. The relative standard deviation (RSD) of the detection associated with the probe in the presence of the cationic micelle was $2 \%$. It is important to mention that lesser values to $5 \%$ are accepted. ${ }^{28}$

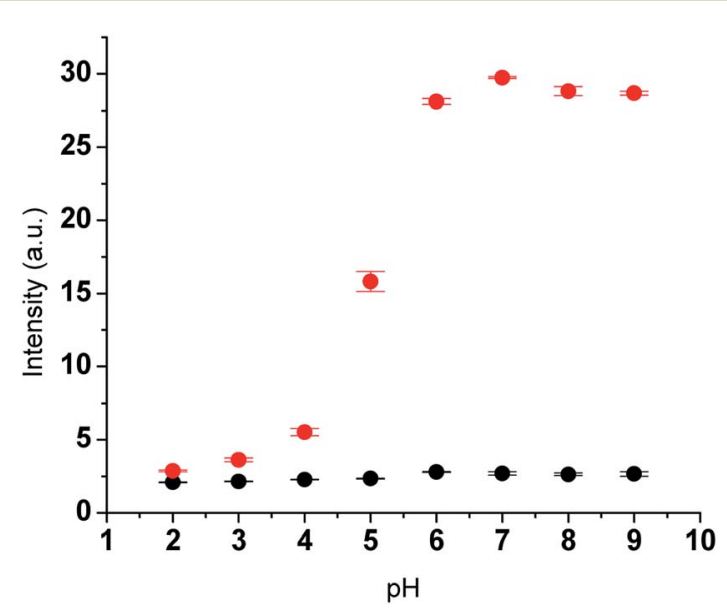

Fig. 1 Effect of pH on the fluorescence intensity of the ChC16 $(5 \mu \mathrm{M})$ alone $(\bullet)$ and after its reaction with $\mathrm{Na}_{2} \mathrm{SO}_{3}(10 \mu \mathrm{M})(\bullet)$ at $25^{\circ} \mathrm{C}$ after $120 \mathrm{~min}$ of reaction. Emission at $485 \mathrm{~nm}$ was measured. $\lambda_{\mathrm{ex}}=450 \mathrm{~nm}$. Slits $5 \mathrm{~nm}$. 

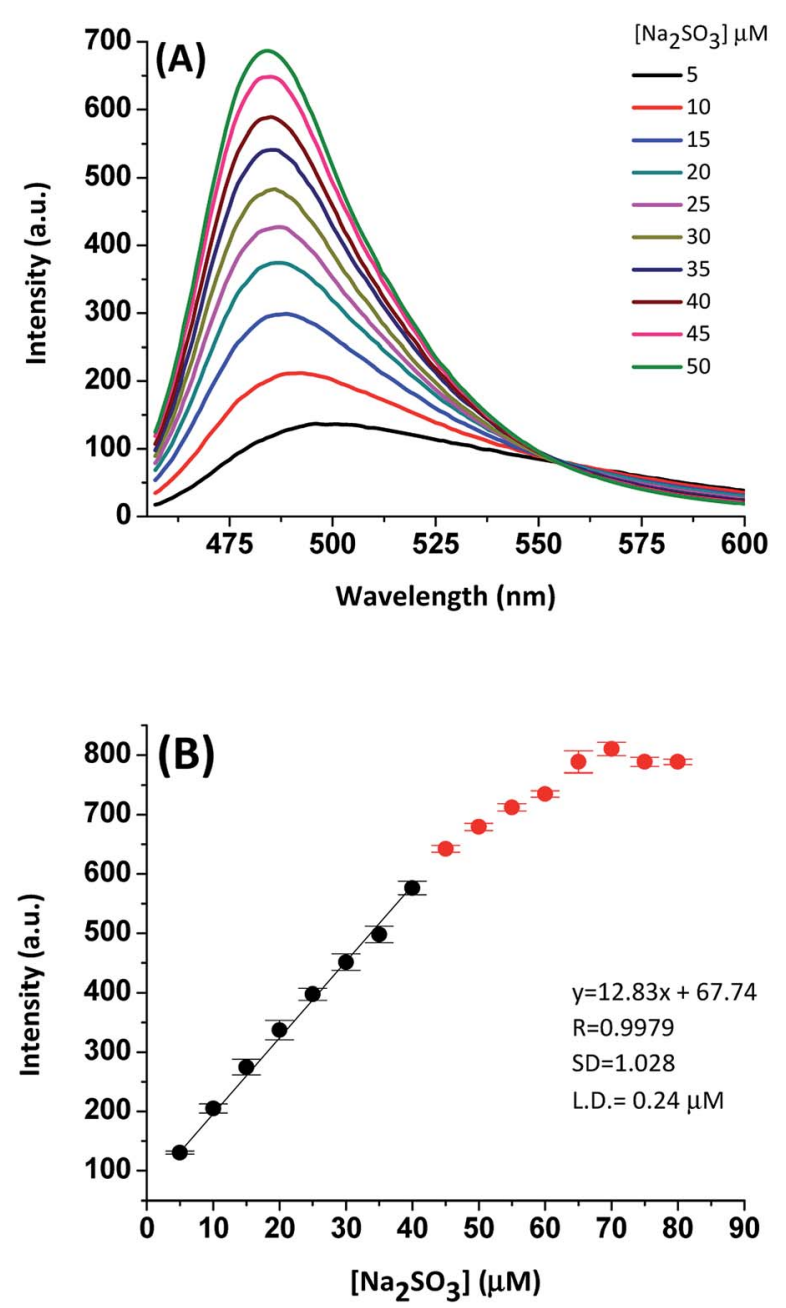

Fig. 2 (A) Fluorescence spectra of $\mathrm{ChC} 16(10 \mu \mathrm{M})$ upon the addition of increasing concentration of $\mathrm{Na}_{2} \mathrm{SO}_{3}$ from 5 to $50 \mu \mathrm{M}$ in BrittonRobinson (BR) buffer solution ( $20 \mathrm{mM}, \mathrm{pH} 7,1 \% \mathrm{DMSO}$ ) in the presence of $1.5 \mathrm{mM}$ of $\mathrm{CPB} ; \lambda_{\mathrm{ex}}=450 \mathrm{~nm}$. (B) Changes in fluorescence intensity of $\mathrm{ChC16}$ at $480 \mathrm{~nm}$ upon the gradual addition of $\mathrm{Na}_{2} \mathrm{SO}_{3}$ from 5 to 80 $\mu \mathrm{M} ; \lambda_{\mathrm{ex}}=485 \mathrm{~nm}$; slits, $5 \mathrm{~nm}$.

\subsection{Selectivity and competition studies of the probe ChC16} toward $\mathrm{SO}_{2}$-derivatives over other analytes

With the aim to evaluate the selectivity of the tested probe (ChC16) toward $\mathrm{SO}_{2}$ derivatives, we investigate its fluorescence response to typical interfering anions such as $\mathrm{F}^{-} ; \mathrm{Cl}^{-} ; \mathrm{Br}^{-} ; \mathrm{I}^{-}$; $\mathrm{NO}_{3}{ }^{-} ; \mathrm{NO}_{2}{ }^{-} ; \mathrm{SO}_{4}{ }^{2-} ; \mathrm{SCN}^{-} ; \mathrm{S}_{2} \mathrm{O}_{3}{ }^{2-} ; \mathrm{S}_{2} \mathrm{O}_{4}{ }^{2-} ; \mathrm{S}^{2-} ; \mathrm{CH}_{3} \mathrm{COO}^{-} ;$ $\mathrm{HCO}_{3}{ }^{-} ; \mathrm{H}_{2} \mathrm{PO}_{4}^{-}$and biothiols (i.e. cysteine (Cys) and glutathione (GSH)). As illustrated in Fig. 3, no significant variations in the fluorescence emission associated to the probe were observed, for most of these anions, even in the presence of 10 eq. of the anions mentioned above. Except a slight change in the probe intensity was observed when the biothiol (GSH) was assessed.

Furthermore, a competitive analysis of the different tested anions with $\mathrm{HSO}_{3}{ }^{-} / \mathrm{SO}_{3}{ }^{2-}$ was conducted. As shown in Fig. 4, after adding $\mathrm{SO}_{2}$ derivatives into the solution containing other anions, no significant variation in fluorescence intensity associated with ChC16 was found. It can be noted that all the tested

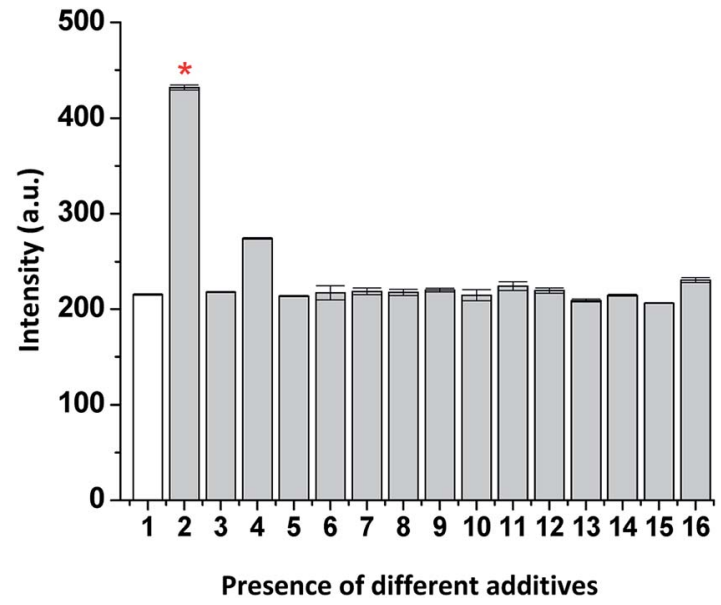

Fig. 3 Fluorescence intensities $\left(\lambda_{\text {ex }}=450 \mathrm{~nm}\right)$ of ChC16 $(10 \mu \mathrm{M})$ upon addition of various anions $(100 \mu \mathrm{M})$ in the presence of $1.5 \mathrm{mM}$ of CPB. White bar represents: ChC16 alone (1) and grey bars represent: $\mathrm{NO}+$ anions (2) $\mathrm{HSO}_{3}^{-}{ }^{-}$*); (3) cysteine; (4) glutathione; (5) $\mathrm{F}^{-}$; (6) $\mathrm{Cl}^{-}$; (7) $\mathrm{Br}^{-}$; (8) $\mathrm{I}^{-}$; (9) $\mathrm{CH}_{3} \mathrm{COO}^{-}$; (10) $\mathrm{NO}_{2}^{-}$; (11) $\mathrm{NO}_{3}^{-}$; (12) $\mathrm{HCO}_{3}^{-}$; (13) $\mathrm{H}_{2} \mathrm{PO}_{4}^{-}$; (14) $\mathrm{SO}_{4}^{2-}$; (15) $\mathrm{S}_{2} \mathrm{O}_{3}{ }^{2-} ;(16) \mathrm{S}^{2-}$. Slits $5 \mathrm{~nm}$. The symbol (*) represents the analyte of interest.

anions have no interference with the fluorescence response of ChC16 toward $\mathrm{HSO}_{3}{ }^{-} / \mathrm{SO}_{3}{ }^{2-}$, thereby indicating its high selectivity.

\subsection{Sensing mechanism of the probe $\mathrm{ChC16}$ toward $\mathrm{SO}_{2}-$ derivatives}

Considering that both $\mathrm{HSO}_{3}{ }^{-} / \mathrm{SO}_{3}{ }^{2-}$ can be acting as nucleophiles, we proposed that their addition to the double bond $(\mathrm{C}=\mathrm{C})$ of the probe could be responsible for the change in the fluorescence emission.

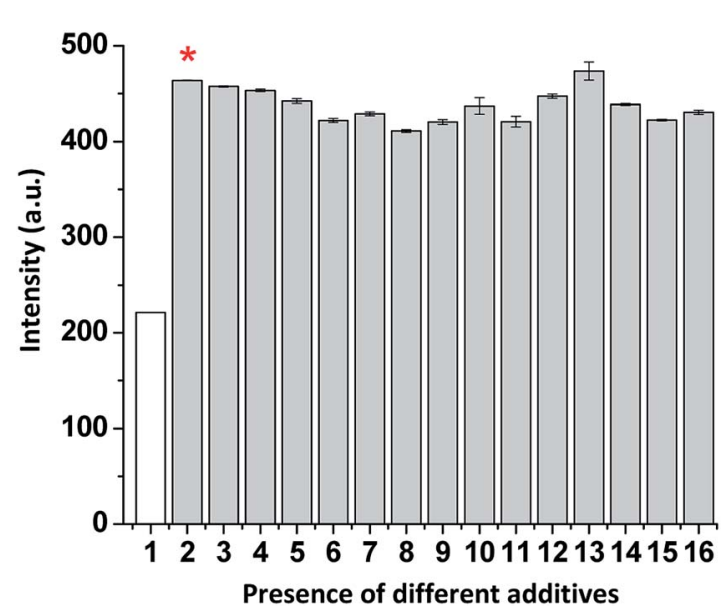

Fig. 4 Fluorescence intensities $\left(\lambda_{\mathrm{ex}}=450 \mathrm{~nm}\right)$ of ChC16 $(10 \mu \mathrm{M})$ upon addition of various anions $(100 \mu \mathrm{M})$ in the presence of $1.5 \mathrm{mM}$ of CPB. White bar represents: ChC16 alone (1) and grey bars represent: $\mathrm{ChC16}$ in the presence of $\mathrm{HSO}_{3}{ }^{-}$(2) and other anions; (3) cysteine; (4) glutathione; (5) $\mathrm{F}^{-}$; (6) $\mathrm{Cl}^{-}$; (7) $\mathrm{Br}^{-}$; (8) $\mathrm{I}^{-}$; (9) $\mathrm{CH}_{3} \mathrm{COO}^{-}$; (10) $\mathrm{NO}_{2}^{-}$; (11) $\mathrm{NO}_{3}{ }^{-}$; (12) $\mathrm{HCO}_{3}{ }^{-}$; (13) $\mathrm{H}_{2} \mathrm{PO}_{4}^{-}$; (14) $\mathrm{SO}_{4}{ }^{2-}$; (15) $\mathrm{S}_{2} \mathrm{O}_{3}{ }^{2-}$; (16) $\mathrm{S}^{2-}$. Slits $5 \mathrm{~nm}$. The symbol (*) represents the analyte of interest. 
In order to confirm the proposed mechanism for the response of the probe after its interaction with $\mathrm{HSO}_{3}{ }^{-} / \mathrm{SO}_{3}{ }^{2-}$, first we carried out experiments using high resolution mass spectroscopy (HRMS-ESI).

Results from the HRMS-ESI (Fig S6; ESI $\dagger$ ) show a major ion peak found at $m / z 435.1598$ which is nearly identical to the theoretical molecular mass of the ChC16-bisulfite adduct $\left([\text { ChC16-H }]^{+}\right.$calcd 435.0858). These data strongly support the $1: 1$ adduct formation of probe ChC16 mainly with bisulfite (ChC16- $\mathrm{SO}_{3} \mathrm{H}$ ).

Subsequently, we assessed the interaction mode between ChC16 and bisulfite using ${ }^{1} \mathrm{H}$-NMR spectroscopy. As shown in Fig. 5A, the spectrum of ChC16 in the absence of $\mathrm{Na}_{2} \mathrm{SO}_{3}$ depicts two important signals at 7.93 and $7.75 \mathrm{ppm}$, which could be attributed to the vinylic protons $\mathrm{H}_{\mathrm{b}}$ and $\mathrm{H}_{\mathrm{a}}$, respectively. Upon the addition of $\mathrm{Na}_{2} \mathrm{SO}_{3}$ to a solution containing the probe, the resulting spectrum presents a new signal that appears at 5.08 ppm (Fig. 5(B)), which is attributed to the proton $\mathrm{H}_{\mathrm{b}}$ that was upfield shifted. These data suggest that the reaction between bisulfite and ChC16 is a Michael addition in the $\beta$ carbon of the ketone $\alpha, \beta$-unsaturated. This result is consistent with the formation of the $\mathbf{C h C 1 6}-\mathrm{SO}_{3} \mathrm{H}$ adduct.

\subsection{Validation and application to real samples}

In order to demonstrate the applicability of the tested probe, compound ChC16 was assessed to detect $\mathrm{HSO}_{3}{ }^{-}$in real samples. In the first case, the real sample included white wines, which were analyzed using probe ChC16 in the presence of CPB as a fluorometric method and a reported method to determine the total sulfite concentration. ${ }^{29}$ As shown in Table 2, the obtained results using these two detection methods for bisulfite perfectly fit (error range 4-9\%). Thus, these results suggest that probe ChC16, in the presence of a cationic micelle as CPB, can be used for quantitative detection of $\mathrm{HSO}_{3}{ }^{-}$in a real sample.

Furthermore, bearing in mind evidence on the production of sulfur dioxide in cytosols and mitochondria of cells ${ }^{30}$ we also assessed whether the probe can determine $\mathrm{SO}_{2}$ derivatives in biological systems. As shown in Fig. 6(A), when SH-SY5Y

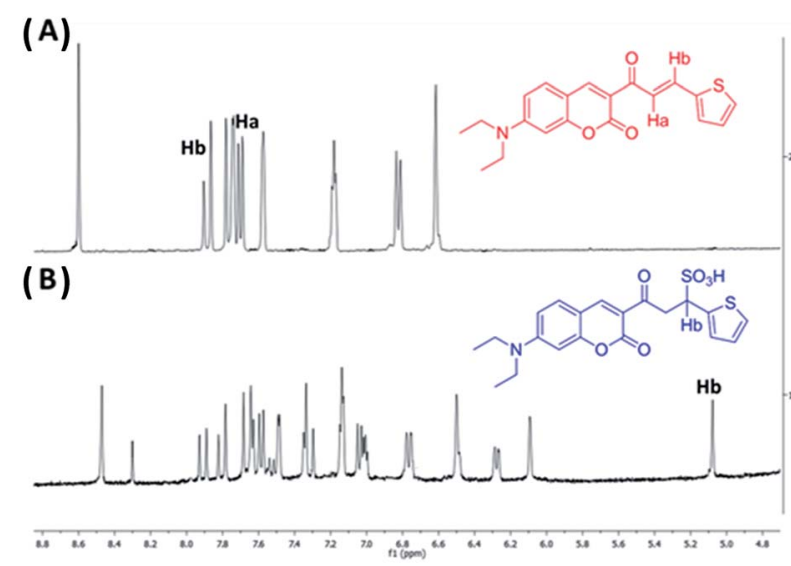

Fig. $5{ }^{1} \mathrm{H}$-NMR partial of $\mathrm{ChC} 16$ in the absence $(\mathrm{A})$ and in the presence (B) of $\mathrm{Na}_{2} \mathrm{SO}_{3}\left(10\right.$ eq.), solvent used DMSO- $d_{6}: \mathrm{D}_{2} \mathrm{O}(4: 1)$.
Table 2 Determination of bisulfite concentration in real samples, see details in Experimental section

\begin{tabular}{lll}
\hline Sample & $\begin{array}{l}\text { Fluorometric method } \\
\text { using ChC16 + CPB }\end{array}$ & $\begin{array}{l}\text { AOAC Official } \\
\text { Method }^{29}\end{array}$ \\
\hline Wine 1 & $104.7\left[\mathrm{mg} \mathrm{L}^{-1}\right]$ & $100.3\left[\mathrm{mg} \mathrm{L}^{-1}\right]$ \\
Wine 2 & $115.3\left[\mathrm{mg} \mathrm{L}^{-1}\right]$ & $119.6\left[\mathrm{mg} \mathrm{L}^{-1}\right]$
\end{tabular}

neuroblastoma cells were incubated with ChC16 (5 $\mu \mathrm{M})$ for about $20 \mathrm{~min}$ at $37{ }^{\circ} \mathrm{C}$, a low intracellular fluorescence was observed, with cytoplasmic accumulation. After treatment of cells with $\mathrm{Na}_{2} \mathrm{SO}_{3}(30 \mu \mathrm{M})$ for an additional $45 \mathrm{~min}$ at $37^{\circ} \mathrm{C}$, a slight increase in the fluorescence signal was detected (not shown).

However, other experiments demonstrated that, when $\mathrm{SH}$ SY5Y cells were incubated with ChC16 $(5 \mu \mathrm{M})$ in the presence of the cationic micelle $\mathrm{CPB}(1 \mathrm{mM})$ and $\mathrm{Na}_{2} \mathrm{SO}_{3}$ for an additional $15 \mathrm{~min}$ at $37{ }^{\circ} \mathrm{C}$, a large increase in fluorescent intensity could be observed. Thus, demonstrating that the compound ChC16 acts as a probe "turn on" induced by the mixture $\mathrm{CPB}-\mathrm{SO}_{2}$ derivatives. Finally, it is important to mention that the ChC16 compound has a diethylamino group at the C-7 of the coumarin and this group have shown affinity for the cell membrane. ${ }^{25}$ However, in this study it was observed that the compound have no affinity by cell membrane. Moreover, an accumulation in cytoplasmic structures was observed.
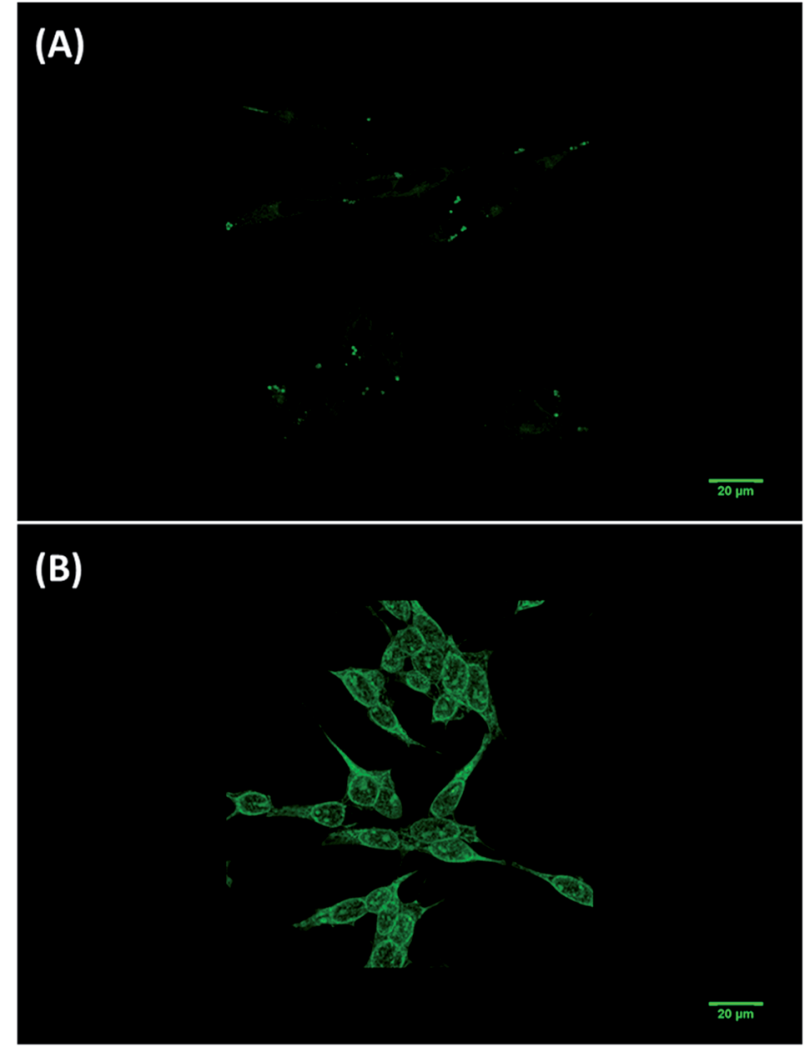

Fig. 6 Fluorescence images of SH-SY5Y cells. (A) Cells were incubated with probe ChC16 (5 $\mu \mathrm{M})$ for $20 \mathrm{~min}$; $(\mathrm{B})$ image of cells after subsequent treatment with $\mathrm{CPB}(1 \mathrm{mM})$ and $\mathrm{Na}_{2} \mathrm{SO}_{3}(30 \mu \mathrm{M})$ for $15 \mathrm{~min}$. 


\section{Conclusions}

In this work, we synthesized and characterized a new chalcocoumarin derivative and we assessed its photo-physical behavior as a sensor for $\mathrm{SO}_{2}$ derivatives. We found that this probe, in the presence of a cationic micellar medium, displays a high selectivity for sulfite over the other typical interferents (biothiols) with a detection limit next to $10^{-9} \mathrm{M}$. Finally, we were able to carry out experiments in real samples of white wine and cell imaging to visualize bisulfite by the proposed fluorometric method, using ChC16 in a micellar cationic media.

\section{Experimental}

\subsection{Synthetic procedures}

4.1.1 Synthesis of $(E)-3-(3-(1 H$-pyrrol-2-yl)acryloyl)-7-(diethylamino)-2H-chromen-2-one. 4-Diethylaminosalicylaldehyde (1) $(2.0 \mathrm{~g}, 10.4 \mathrm{mmol})$, ethyl acetoacetate $(2.6 \mathrm{~g}, 20 \mathrm{mmol})$, piperidine $(0.5 \mathrm{~mL})$ and one drop of $\mathrm{AcOH}$, were combined in absolute $\mathrm{EtOH}$ $(60 \mathrm{~mL})$ and refluxed for $6 \mathrm{~h}$ and cyclized in a single step to afford obtaining the compound 3-acetyl-7-(diethylamino)-2H-chromen2-one (2). Subsequently, compound 2 (0.5 g, $1.9 \mathrm{mmol})$ and 2thiophenecarboxaldehyde $(0.2 \mathrm{~g}, 1.9 \mathrm{mmol})$ were dissolved in $10 \mathrm{~mL}$ of $\mathrm{EtOH}$ and $0.3 \mathrm{~mL}$ of piperidine were added to this solution. The mixture was kept at reflux temperature for $14 \mathrm{~h}$. The solution was concentrated under reduced pressure. The solid was finally purified by CC on silica gel eluting with DCM : AcOEt $15: 1$. The product obtained is a yellow solid $(0.478 \mathrm{~g}, 1.35 \mathrm{mmol})$ in $71.0 \%$ yield. ${ }^{1} \mathrm{H}-\mathrm{NMR}\left(400 \mathrm{MHz}, \mathrm{DMSO}-d_{6}\right) \delta 8.57(\mathrm{~s}, 1 \mathrm{H}), 7.93$ (d, $1 \mathrm{H}, J=20 \mathrm{~Hz}, \mathrm{Ar}-\mathrm{CH}, \mathrm{H}^{\prime}$ ), 7.75 (d, $1 \mathrm{H}, J=20 \mathrm{~Hz}, \mathrm{CO}-\mathrm{CH}=$, $\mathrm{H}^{\prime}$ ), 7.73 (s, 1H, Ar-H, H4), 7.68 (d, $1 \mathrm{H}, J=12 \mathrm{~Hz}, \mathrm{Ar}-\mathrm{H}, \mathrm{H}_{4}^{\prime \prime}$ ), 7.56 (d, $1 \mathrm{H}, J=12 \mathrm{~Hz}, \mathrm{Ar}-\mathrm{H}, \mathrm{H} 6, \mathrm{H} 8), 7.17$ (t, 1H, $J=4.0 \mathrm{~Hz}, \mathrm{Ar}-\mathrm{H}$, H6), 6.80 (d, 1H, $J=4.0 \mathrm{~Hz}, \mathrm{Ar}-\mathrm{H}, \mathrm{H} 6), 6.59$ (s, 1H), 3.50 (dd, $4 \mathrm{H}, J$ $\left.=8.0,-\mathrm{CH}_{2}-\right), 1.15\left(\mathrm{~s}, 6 \mathrm{H}, J=8.0,-\mathrm{CH}_{3}\right) .{ }^{13} \mathrm{C}-\mathrm{NMR}(100 \mathrm{MHz}$, DMSO- $\left.d_{6}\right) 12.8,44.9,96.3,108.4,110.7,115.6,124.0,129.2,130.2$, $133.0,133.4,135.5,140.7,148.9,153.3,158.7,160.5,185.3$. The $m /$ $z$ observed value was 354.1148 positive mode, and the calculated value for $\mathrm{C}_{20} \mathrm{H}_{19} \mathrm{NO}_{3} \mathrm{~S}$ was 353.1085 (Fig. S3 $\dagger$ ).

\subsection{Materials and methods}

Solvents and reagents utilized were Sigma-Aldrich. All solutions employed in this study were prepared in Britton-Robinson (BR) buffer solution $(20 \mathrm{mM}, \mathrm{pH}=7)$ and the reagents utilized were Suprapur®. The stock dissolution of the probe was conducted in DMSO. Absorption and fluorescence spectra were obtained HP-8453 diode array spectrophotometer and Cary Eclipse fluorescence spectrophotometer, respectively.

4.2.1 High-resolution mass spectrometry (HRMS-ESI) studies. High-resolution mass spectra (HRMS-ESI) were extracted from high resolution mass spectrometer Exative ${ }^{\mathrm{TM}}$ Plus Orbitrap, ThermoFisher Scientific. The analysis for the reaction products was performed with the following scan parameters: resolution 140.000; AGC target 1e6; inject time 200. HESI source was heath gas flow 8 ; auxiliary gas flow rate 3 ; sweep gas flow rate 0 ; capillary temperature $250{ }^{\circ} \mathrm{C}$, S-lens RF 100; heater temperature $100{ }^{\circ} \mathrm{C}$, at mode positive with spray voltage $2.8 \mathrm{kV}$.
4.2.2 Nuclear magnetic resonance (NMR) studies. ${ }^{1} \mathrm{H}$ and ${ }^{13} \mathrm{C}$ NMR spectra were obtained at $25^{\circ} \mathrm{C}$ on a Bruker Avance 400 $\mathrm{MHz}$ spectrometer using TMS as an internal standard. The NMR spectra were processed with MestreNova software v9.0. All solutions were prepared by mixing appropriate volumes of stock solutions of ChC16 in DMSO- $d_{6}$ and $\mathrm{D}_{2} \mathrm{O}$.

4.2.3 Determining the quantum yield of emission. Fluorescence quantum yields ChC16 were measured using a solution of quinine sulfate in $0.5 \mathrm{M} \mathrm{H}_{2} \mathrm{SO}_{4}$ as standard $(\Phi \mathrm{S}=0.546)^{31}$ for probe. All values were corrected taking into account the solvent refraction index. Quantum yields were calculated using eqn (1), ${ }^{31}$ where the subscripts $\mathrm{x}$ and $\mathrm{s}$ denote sample and standard, respectively, $\Phi$ is the quantum yield, $\eta$ is the refractive index, and Grad is the slope from the plot of integrated fluorescence intensity $v s$. absorbance.

$$
\Phi_{\mathrm{x}}=\Phi_{\mathrm{s}}\left(\frac{\operatorname{Grad}_{\mathrm{x}}}{\operatorname{Grad}_{\mathrm{s}}}\right)\left(\frac{\eta_{\mathrm{x}}{ }^{2}}{\eta_{\mathrm{x}}{ }^{2}}\right)
$$

4.2.4 Reproducibility. The stability of the method was determined into measuring the intensity of fluorescence in the wavelength of the peak of emission in the presence of CPB for 30 successive measures each 5 minutes. The shrunk data were examined in the software Origin 8.0.

4.2.5 Detection limit. The detection limit (LOD) was calculated based on fluorescence of the successive additions of the probe. To determine the $\mathrm{S} / \mathrm{N}$ ratio, the emission intensity of each probe with $\mathrm{Na}_{2} \mathrm{SO}_{3}$ was measured for three times and the standard deviation of calibration curve was determined. The LOD was calculated from $\operatorname{LOD}_{(y)}=a+3 \sigma_{x / y}$ and $\operatorname{LOD}_{(y)}=a+$ $b \mathrm{LOD}$, where $a$ is the intercept, $\sigma_{x / y}$ is the random error in $x$ and $y$, and $b$ is the slope of the plot of fluorescence intensity versus sample concentration. ${ }^{21}$ In addition, $\operatorname{LOD}=\operatorname{LOD}_{(x)}=3 \sigma_{x / y} / b$, assuming that errors principally occur in the $y$-direction.

4.2.6 Preparation of real samples. The studied samples were commercial white wines. For this, $30 \mathrm{~mL}$ of a newly opened wine bottle was taken and $5 \mathrm{~g}$ of activated carbon was added. After $30 \mathrm{~min}$, the sample was filtered with syringe filters 0.45 micron to remove carbon. Subsequently each sample was added to the fluorescence cuvette, it contained Britton-Robinson (BR) buffer solution (20 mM, pH 7, 1\% DMSO) in the presence of $1.5 \mathrm{mM}$ of CPB. Subsequently, successive additions of $\mathrm{Na}_{2} \mathrm{SO}_{3}$ were carried out and using the standard addition method. The concentration of the sample was determined.

4.2.7 Cell culture and fluorescence imaging. SH-SY5Y neuroblastoma cell lines (CRL-2266, American Type Culture Collection, Rockville, MD) were cultured in MEM/F12 medium supplemented with $10 \%$ fetal bovine serum (FBS), non-essential amino acids, antibiotic-antimycotic mixture, and $20 \mathrm{mM}$ HEPES buffer, $\mathrm{pH}$ 7.4. The medium was replaced every 2 days. Cells were exposed and incubated with, ChC16 (5 $\mu \mathrm{M}, 20 \mathrm{~min}$ ) and the basal fluorescence of the probe was measured. In other cases, adding one mix incubated with ChC16 $(5 \mu \mathrm{M})$ in the presence of the cationic micelle CPB $(1 \mathrm{mM}), \mathrm{Na}_{2} \mathrm{SO}_{3}(30 \mu \mathrm{M})$ for about $15 \mathrm{~min}$, and washed with HBSS with calcium and magnesium salts, after that the fluorescence was determined. 
The fluorescence change was measured and observed using a confocal microscopy at $63 \times$ amplification. Confocal microscopy Zeiss 710.

\section{Conflicts of interest}

There are no conflicts to declare.

\section{Acknowledgements}

This work was supported by FONDECYT postdoc grant \#3150196, FONDECYT grants \#1170753 and \#11170701, and by COLCIENCIAS Grants \#130774559056 Colombia.

\section{References}

1 R. F. McFeeters and A. O. Barish, J. Agric. Food Chem., 2003, 51, 1513-1517.

2 C. Wang, S. Feng, L. Wu, S. Yan, C. Zhong, P. Guo, R. Huang, X. Weng and X. Zhou, Sens. Actuators, B, 2014, 190, 792-799.

3 X. Ma, C. Liu, Q. Shan, G. Wei, D. Wei and Y. Du, Sens. Actuators, B, 2013, 188, 1196-1200.

4 S. L. Bahna and J. G. Burkhardt, Allergy Asthma Proc., 2018, 39, 3-8.

5 M.-Y. Wu, T. He, K. Li, M.-B. Wu, Z. Huang and X.-Q. Yu, Analyst, 2013, 138, 3018-3025.

6 U.S. Food and Drug Adminitration, 1986, 51, 25012-25020.

7 J. M. Vahl and J. E. Converse, J. -Assoc. Off. Anal. Chem., 1980, 63, 194-199.

8 D. R. Migneault, Anal. Chem., 1989, 61, 273-275.

9 Z. Zhong, G. Li, B. Zhu, Z. Luo, L. Huang and X. Wu, Food Chem., 2012, 131, 1044-1050.

10 Ü. T. Yilmaz and G. Somer, Anal. Chim. Acta, 2007, 603, 3035.

11 A. Isaac, J. Davis, C. Livingstone, A. J. Wain and R. G. Compton, TrAC, Trends Anal. Chem., 2006, 25, 589-598.

12 M. H. Pournaghi-Azar, M. Hydarpour and H. Dastangoo, Anal. Chim. Acta, 2003, 497, 133-141.

13 C. Ruiz-Capillas and F. Jimenez-Colmenero, Food Addit. Contam., Part A, 2008, 25, 1167-1178.

14 S. S. M. Hassan, M. S. A. Hamza and A. H. K. Mohamed, Anal. Chim. Acta, 2006, 570, 232-239.
15 J. Chao, X. Wang, Y. Liu, Y. Zhang, F. Huo, C. Yin, M. Zhao, J. Sun and M. Xu, Sens. Actuators, B, 2018, 272, 195-202.

16 J. Chao, H. Wang, Y. Zhang, C. Yin, F. Huo, J. Sun and M. Zhao, New J. Chem., 2018, 42, 3322-3333.

17 J. Chao, Y. Liu, Y. Zhang, Y. Zhang, F. Huo, C. Yin, Y. Wang and L. Qin, Spectrochim. Acta, Part A, 2015, 146, 33-37.

18 J. Chao, Y. Zhang, H. Wang, Y. Zhang, F. Huo, C. Yin, L. Qin and Y. Wang, Sens. Actuators, B, 2013, 188, 200-206.

19 Y. Yang, F. Huo, J. Zhang, Z. Xie, J. Chao, C. Yin, H. Tong, D. Liu, S. Jin, F. Cheng and X. Yan, Sens. Actuators, B, 2012, 166-167, 665-670.

20 H. Tian, J. Qian, Q. Sun, H. Bai and W. Zhang, Anal. Chim. Acta, 2013, 788, 165-170.

21 M. Gómez, E. G. Perez, V. Arancibia, C. Iribarren, C. BravoDíaz, O. García-Beltrán and M. E. Aliaga, Sens. Actuators, B, 2017, 238, 578-587.

22 O. García-Beltrán, C. González, E. G. Pérez, B. K. Cassels, J. G. Santos, D. Millán, N. Mena, P. Pavez and M. E. Aliaga, J. Phys. Org. Chem., 2012, 25, 946-952.

23 M. E. Aliaga, W. Tiznado, B. K. Cassels, M. T. Nuñez, D. Millán, E. G. Pérez, O. García-Beltrán and P. Pavez, $R S C$ Adv., 2014, 4, 697-704.

24 K. Peter, T. Stefan, S. Hans-Günther and A. Andreas, Eur. J. Org. Chem., 2004, 1577-1583.

25 O. García-Beltrán, N. Mena, O. Yañez, J. Caballero, V. Vargas, M. T. Nuñez and B. K. Cassels, Eur. J. Med. Chem., 2013, 67, 60-63.

26 O. García-Beltrán, N. Mena, E. G. Pérez, B. K. Cassels, M. T. Nuñez, F. Werlinger, D. Zavala, M. E. Aliaga and P. Pavez, Tetrahedron Lett., 2011, 52, 6606-6609.

27 J. Wang, Y. Hang, H. Tan, T. Jiang, X. Qu and J. Hua, J. Photochem. Photobiol., A, 2017, 346, 265-272.

28 D. Jiang, H. Jiang, J. Ji, X. Sun, H. Qian, G. Zhang and L. Tang, J. Agric. Food Chem., 2014, 62, 6473-6480.

29 AOAC Official Method 990.28, Sulfites in Foods, Optimized Monier-Williams Method, AOAC Official Methods of Analysis, Sec. 47.3.43, 2000.

30 D.-P. Li, Z.-Y. Wang, J. Cui, X. Wang, J.-Y. Miao and B.-X. Zhao, Sci. Rep., 2017, 7, 45294.

31 G. A. Crosby and J. N. Demas, J. Phys. Chem., 1971, 75, 9911024. 